
\title{
O Serviço Social e as
condições de trabalho no
Suas: tensões e desafios à materialização do projeto profissional
}

\author{
Social Work and working conditions in the ITS: tensions and \\ challenges to materialize professional project
}

Senir Santos da Hora*

\begin{abstract}
Resumo - O presente artigo versa sobre os desafios postos à profissão, na atualidade, frente às formas de efetivação do projeto ético-político profissional. Assim, é fruto das minhas inquietações sobre os dilemas do trabalho do assistente social no Sistema Único de Assistência Social (Suas). Nesse sentido, o texto apresenta reflexões teóricas em torno das abordagens contemporâneas sobre a relação entre o Serviço Social e o projeto profissional, mediado pelo recorte das condições de trabalho na política da Assistência Social no município de Rio Bonito (RJ), nos seus respectivos equipamentos: Centro de Referência da Assistência Social (Cras ${ }^{1}$ ) e Centro de Referência Especializado da Assistência Social $\left(\mathrm{Creas}^{2}\right)$, no período de 2012 a 2013. Isto, a partir da identificação das possibilidades e limites que o assistente social encontra na condução do trabalho e para integral efetivação do Projeto Ético-Político da profissão.
\end{abstract}

Palavras-chave: trabalho assalariado; Suas; assistente social; projeto profissional.

\begin{abstract}
This article deals with the challenges faced by the profession today concerning the realization of the ethical-political professional project, and is the fruit of my concerns about the dilemmas of social workers in the ITS. In this sense, this text presents theoretical reflections on the contemporary approaches to the relation between Social Work and the professional project, mediated by the outline of working conditions in the social assistance policy in the municipality of Rio Bonito, Rio de Janeiro. It goes on to analyze their respective apparatuses, Cras and Creas, in the period of 2012-2013, emerging from the identification of the possibilities and limits the social worker finds in the practice of his work and the full realization of its ethical-political professional project.

Keywords: wage labor; ITS; social worker; professional project.
\end{abstract}

\footnotetext{
* Assistente Social do Ministério da Saúde (INCA) - RJ e Doutoranda em Serviço Social no Programa de Pós-Graduação em Serviço Social da Universidade do Estado do Rio de Janeiro (PPGSS/UERJ). Correspondência: Rua Califórnia, 533, Centro- São Gonçalo- RJ, CEP: 24465-120. E-mail: <senirsantos@hotmail.com>

${ }^{1} \mathrm{O}$ Cras oferta serviços de proteção social básica, que visam à prevenção de situações de risco e ao fortalecimento de vínculos familiares e comunitários (PNAS, 2004).

${ }^{2} \mathrm{O}$ Creas oferta serviços de proteção social especial de média complexidade destinados a indivíduos com direitos violados, mas sem o rompimento dos vínculos familiares e comunitários (PNAS, 2004).
} 


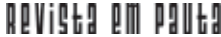

\} O SERVIÇO SOCIAL E AS CONDIÇÕES DE TRABALHO - HORA, S. S. |

DOI: 10.12957/rep.2015.21056

\section{Introdução}

É notório como as transformações contemporâneas vêm afetando o mundo do trabalho assalariado, submetendo a atividade profissional aos dilemas da alienação, seus processos e sujeitos. Associa-se a esse contexto as redefinições profundas no Estado e nas políticas sociais, que desencadearam novas requisições, demandas, dilemas e possibilidades ao trabalho do assistente social. Mudanças que expõem desafios à consolidação do projeto profissional crítico no âmbito dos processos de trabalho. A "desregulamentação" e a "flexibilização" que o grande capital vem implementando nas relações e condições de trabalho afetam não só os padrões de produção consolidados, como também os direitos laborais conquistados pela classe trabalhadora.

Essa pesquisa reconhece o assistente social como trabalhador assalariado e as dimensões do seu trabalho como concreto e abstrato (IAMAMOTO, 2007). Delineia, assim, o contexto de construção do Projeto ÉticoPolítico do Serviço Social brasileiro com um processo conhecido como de intenção de ruptura ou renovação da profissão (NETTO, 1991). Ainda, evidencia que a efetivação do projeto profissional do Serviço Social é tensionada pela condição de assalariamento de seus profissionais e pela construção democrática de espaços coletivos, juntamente com outras categorias profissionais e movimentos sociais.

Em termos metodológicos, buscamos investigar as determinações que incidem na caracterização do atual espaço sócio-ocupacional do Serviço Social, no âmbito da Assistência Social, apreendendo as condições de trabalho e a materialização do seu Projeto Ético-Político Profissional no contexto neoliberal. O referencial teórico-metodológico adotado está apoiado na concepção histórica do pensamento crítico-dialético, que parte dos dados fornecidos pela realidade concreta e examina o conjunto de suas determinações históricas, observando a relação entre o particular e o universal ${ }^{3}$.

$\mathrm{Na}$ pesquisa, partimos do pressuposto de que o conhecimento exige o contato com a realidade. Isto porque, antes de elevar-se em nível teórico, o conhecimento começa pela prática. Essa prática permite uma ação consciente do ser social, que se dirige para a intervenção, uma vez que nos põe em contato direto com as realidades objetivas (NETTO, 2009a).

Segundo Ianni (2011), o conhecimento ou o pensamento não nascem prontos; eles são atravessados por transformações e reorientações. Nesse sentido, podemos afirmar que o conhecimento, enquanto "fato prático, social e histórico" (LEFÉBVRE, 1975), permite a interação dialética entre sujeito e objeto. Isto é, não se trata de uma relação de externalidade,

\footnotetext{
3 "O que torna a ciência necessária é o fato de a realidade não ser transparente. A aparência e a essência dos fenômenos não coincidem, embora uma revele elementos da outra. Portanto, o que é dialético é a própria realidade" (GOHN, 1984, p. 4).
} 


\section{ReVigta dil pollt}

\} O SERVIÇO SOCIAL E AS CONDIÇÕES DE TRABALHO - HORA, S. S.

DOI: $10.12957 /$ rep.2015.21056

mas uma relação entre dois elementos opostos, "indissoluvelmente" ligados entre si (NETTO, 2009a).

Para obtenção do conhecimento concreto do objeto, em suas múltiplas determinações, foram realizadas entrevistas individuais semiestruturadas ${ }^{4} \mathrm{com}$ as assistentes sociais dos referidos equipamentos (três Centros de Referência da Assistência Social - Cras e um Centro de Referência Especializado da Assistência Social - Creas do município de Rio Bonito RJ).

O processo investigativo foi realizado no período entre 2012 e 2013, contando com a participação de seis assistentes sociais. Estas encontravam-se em pleno exercício do trabalho nas instituições da esfera pública estatal, no âmbito da política de Assistência Social da Prefeitura Municipal de Rio Bonito (RJ). A proposta investigativa foi submetida à Comissão Científica da Faculdade de Serviço Social da Universidade Federal Fluminense (UFF) e às normas éticas destinadas à pesquisa envolvendo seres humanos da Comissão Nacional de Ética em Pesquisa (Conep). O depoimento dos profissionais foi abordado na sistematização da pesquisa de forma anônima.

Nessa etapa resgatamos, ainda, a inserção do Serviço Social nos equipamentos estudados, além de identificar o processo de trabalho coletivo no qual se inscreve o assistente social e suas particularidades, pois esses espaços possuem racionalidades distintas na divisão social e técnica do trabalho (ALMEIDA; ALENCAR, 2011). A partir de análise de dados qualitativos, obtidos nas entrevistas semiestruturadas, na sistematização de experiências, na observação participante e na pesquisa documental, destacamos a atuação do assistente social junto aos usuários dos serviços nos Cras e Creas, apresentando a metodologia que associa as ações profissionais a um trabalho socioeducativo.

O questionamento norteador desta pesquisa comunga com o conhecimento do processo de trabalho coletivo em que se inscreve o assistente social, na condição de trabalhador assalariado. Nesse sentido, torna-se necessário indagar sobre qual o nosso desafio profissional, pensando as tensões entre projeto profissional e trabalho assalariado. Assim, quais as possibilidades e limites de fortalecimento do projeto profissional, numa arena de desmonte de direitos e de precarização das condições e relações laborais?

Consideramos, enquanto hipóteses, as seguintes afirmações:

- As respostas dos assistentes sociais às demandas dos usuários, que buscam pelo Serviço Social na política de Assistência Social no município estudado, não têm sido mediadas pelos princípios e diretrizes do Projeto Ético-Político Profissional. Isto porque elas são dadas através de uma atuação imediata e pontual, sem um planejamento necessário.

\footnotetext{
${ }^{4}$ Segundo Cruz Neto (1994), as entrevistas semiestruturadas buscam articular duas modalidades ou técnicas: uma diz respeito à entrevista aberta, na qual o entrevistado pode abordar livremente o tema proposto, e a outra modalidade diz respeito à entrevista estruturada, que pressupõe perguntas previamente formuladas.
} 


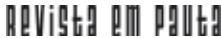

\} O SERVIÇO SOCIAL E AS CONDIÇÕES DE TRABALHO - HORA, S. S. \}

DOI: 10.12957/rep.2015.21056

- As condições sociais que circunscrevem o trabalho do assistente social, com os rebatimentos da "contrarreforma" do Estado, tendem a ser desreguladas e flexibilizadas com a subordinação do conteúdo do trabalho aos objetivos e necessidades das entidades empregadoras. Levando, assim, o assistente social a exercer um trabalho muito mais burocratizado e rotineiro, sob a órbita da alienação, do que um trabalho intelectual, numa perspectiva de dimensão política e pedagógica, no âmbito dos processos de estabelecimento de consensos sociais (IAMAMOTO; CARVALHO, 2012).

- O ingresso dos profissionais nos Centros de Referências (Cras e Creas) se dá na condição de contrato precarizado, por meio de processo seletivo simplificado. Este possui caráter temporário e é crivado pelo tráfico de influências, o que descumpre a prerrogativa constitucional de contratação pela via do concurso público. Logo, esses profissionais se deparam, no cotidiano do espaço sócio-ocupacional, com precárias condições de trabalho, tais quais espaços físicos insuficientes, contratos de trabalho instáveis, insegurança no emprego, baixas remunerações e outros constrangimentos do trabalho assalariado. Essas condições inflexionam as possibilidades de materialização do Projeto Ético-Político Profissional uma vez que impõem uma posição de submissão do profissional no espaço sócioocupacional, comprometendo a qualidade dos serviços e da estratégia de alargamento de sua relativa autonomia.

Com o "novo" modelo de "empregabilidade", que marca a sociedade do capitalismo avançado e que tem seus rebatimentos no trabalho do assistente social - através de contratos, "subcontratos", trabalhos terceirizados sem garantias de direitos -, presenciamos a dificuldade para a continuidade e qualidade dos serviços. Além disso, também para a materialização do projeto profissional, cuja hegemonia tem sido ameaçada pela ausência da busca por estratégias de alargamento da nossa relativa autonomia frente às tensões do trabalho assalariado (IAMAMOTO, 2007).

\section{O processo de trabalho no Suas no município de Rio Bonito (RJ)}

A partir da análise desses dados qualitativos, foi possível identificar o processo de trabalho coletivo no qual se inscreve o assistente social, bem como suas particularidades. Além dessa análise, fizemos também a identificação dos avanços e desafios da política de Assistência Social no município, sob a lógica do Sistema Único de Assistência Social (Suas), e como esta tem sido compreendida pelos assistentes sociais dos referidos equipamentos estudados.

O município de Rio Bonito está localizado na região do Estado do Rio de Janeiro denominada de Baixada Litorânea. O município fica a $80 \mathrm{~km}$ da cidade do Rio de Janeiro, sendo cortada pela BR-101, estrada federal que liga o Rio de Janeiro a todo o país. Dentro da gestão do Suas, o 
município se enquadra na gestão básica. Isto significa que assume a responsabilidade de organizar a Proteção Social Básica e Especial, prevenindo situação de risco por meio do desenvolvimento de potencialidades e aquisições, além de fornecer atendimentos e acompanhamento aos indivíduos ou famílias com direitos violados. Ainda de acordo com a NOBSuas (BRASIL, 2012), Rio Bonito caracteriza-se como município de médio porte, tendo a obrigação de estruturar três Cras, cada um para até 5.000 famílias referenciadas, respeitando a prioridade de áreas com maior vulnerabilidade social. Além disso, também um Creas e uma Instituição de Acolhimento - abrigo para crianças e adolescentes, de 0 a 12 anos incompletos.

Na realidade de Rio Bonito, percebeu-se, através da pesquisa de campo e documental, que a política de Assistência Social na lógica do Suas ainda precisa avançar enquanto um lugar de reconhecimento do protagonismo e de acesso a direitos.

Desde a implantação dos Cras e Creas, percebem-se alguns desafios e dificuldades que ainda precisam ser superados. Estes referem-se à estrutura física dos equipamentos e condições de trabalho, que são precárias e com alta rotatividade dos trabalhadores, à substituição de quadro técnico permanente e qualificado por contratos de trabalhos por tempo determinado, à fragilização da rede, à ausência de recursos e à baixa prioridade por parte da gestão pública municipal com a prestação dos serviços.

Em relação à infraestrutura, constata-se que o grande desafio é a superação da compreensão dos Cras e Creas enquanto simples estruturas improvisadas ou como espaços inadequados. Ainda é predominante o estigma de uma política "pobre", ofertada a uma população "pobre" e por meio de unidades "pobres". Logo, o espaço físico constitui fator determinante para o reconhecimento desses equipamentos como unidade pública que possibilita acesso a direitos.

Quanto à constituição do quadro de recursos humanos com lotação nos Cras e Creas, ainda que seguindo parcialmente as exigências da NOB-RH-Suas de 2006, evidencia-se a predominância dos vínculos por contratos temporários e por comissão.

A Secretaria de Assistência Social do município de Rio Bonito não possuía, entre 2012 e 2013, um gestor técnico com nível superior. Nos Cras, com capacidade de referenciamento de até 5.000 famílias em cada equipamento (BRASIL, 2005), existem 54 funcionários, dentre eles: coordenador, assistente social, psicólogo, educadores, oficineiros, auxiliar de serviços gerais e administrativos. Já no Creas, com capacidade de referenciamento de 150 famílias, existem sete funcionários, entre eles: coordenador, assistente social, psicólogo, advogado, educador social e auxiliar de serviços gerais e administrativos.

A reconstrução do significado de Assistência Social vem sendo o grande desafio para os trabalhadores desta política. Sua contribuição aponta 


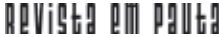

\} O SERVIÇO SOCIAL E AS CONDIÇÕES DE TRABALHO - HORA, S. S. \}

DOI: $10.12957 /$ rep.2015.21056

para o redirecionamento do conteúdo do trabalho e intervenção à nova perspectiva, comprometida com os interesses e as necessidades sociais da população usuária. Como observa uma das entrevistadas, a política de Assistência Social precisa superar a sua tradicional cultura de reiteração da subalternidade e de precarização do trabalho:

O Suas contribuiu para ampliação do acesso aos direitos assistenciais e forneceu mecanismos concretos de organização e direcionamento para profissionais da área. Porém, o ambiente municipal vem dificultando que esses profissionais atuem na concretização dos direitos. São as ausências de recursos e de um espaço físico adequado, assim como os vínculos precários feitos através de processo seletivo obscuro e com alta rotatividade, dificultando as ações de potencialização do trabalho e de capacitação permanente para os profissionais, que precisam ser superados. Quando o profissional é concursado, ele possui maior autonomia para se recusar a participar de manipulações políticas. (Assistente social A - Cras 1).

Quadro I: Recursos Humanos nos Cras e Creas do município de Rio Bonito

\begin{tabular}{|c|c|c|c|c|}
\hline Equipe técnica & $\begin{array}{l}\text { Cras } 1 \text { (número de } \\
\text { funcionários/ tipo } \\
\text { de vínculo) }\end{array}$ & $\begin{array}{c}\text { Cras } 2 \\
\text { (número de } \\
\text { funcionários/ tipo de } \\
\text { vínculo) }\end{array}$ & $\begin{array}{c}\text { Cras } 3 \text { (número de } \\
\text { funcionários/ tipo } \\
\text { de vínculo) }\end{array}$ & $\begin{array}{c}\text { Creas } \\
\text { (número de } \\
\text { funcionários/ tipo de } \\
\text { vínculo) }\end{array}$ \\
\hline Coordenador & 1/concursado & 1/comissionado & 1/concursado & 1/contratado \\
\hline Assistente social & $\begin{array}{c}\text { 2/concursados e } \\
\text { contratados }\end{array}$ & $\begin{array}{c}\text { 2/concursado e } \\
\text { contratado }\end{array}$ & $2 /$ contratados & $2 /$ contratados \\
\hline Psicólogo & 1/contratado & 1/contratado & 1/contratado & 1/comissionado \\
\hline Advogado & 0 & 0 & 0 & 1/comissionado \\
\hline Educador social & $\begin{array}{l}\text { 2/contratado e } \\
\text { comissionado }\end{array}$ & $2 /$ contratados & 1/ contratado & 1/contratado \\
\hline Oficineiro & 13/contratados & $\begin{array}{c}13 /(12 \text { contratados e } \\
1 \text { comissionado) }\end{array}$ & 6/contratados & 0 \\
\hline $\begin{array}{c}\text { Auxiliar de serviços } \\
\text { gerais }\end{array}$ & 1/contratado & 1/concursado & 1/contratado & 1/contratado \\
\hline Auxiliar administrativo & 1/concursado & 1/concursado & 1/contratado & 1/contratado \\
\hline $\begin{array}{c}\text { Total de } \\
\text { funcionários }\end{array}$ & 21 & 21 & 13 & 08 \\
\hline
\end{tabular}

Fonte: documentos internos da Secretaria de Bem-Estar Social do município de Rio Bonito.

A Assistência Social precisa ser entendida como um espaço de lutas e reivindicações da população. Logo, o grande desafio que se coloca, não só para os assistentes sociais, mas para todos os trabalhadores do Suas, é o de romper com a herança perversa de uma pobreza persistente e naturalizada, em uma sociedade cada vez mais atingida pelas iniquidades inscritas na trama social. Desse modo, a fim de tornar a política de Assistência Social 


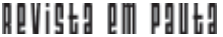

\} O SERVIÇO SOCIAL E AS CONDIÇÕES DE TRABALHO - HORA, S. S.

DOI: $10.12957 /$ rep.2015.21056

mais abrangente, comprometida não apenas com os mínimos sociais, mas com as necessidades sociais dos sujeitos.

\section{O assistente social no Suas: tensões e desafios nas relações de trabalho e na materialização do projeto profissional}

Procuramos mostrar, nessa análise, como a gestão do trabalho na política de Assistência Social vem sofrendo com as consequências das contradições postas pelo modo de produção capitalista, assim como das novas configurações do trabalho e da contrarreforma gerencial do Estado na atual conjuntura.

Com as transformações societárias, no contexto do capitalismo tardio, revelam-se inflexões significativas no conjunto da vida social, as quais incidem fortemente sobre as profissões. Observa-se, portanto, um processo de flexibilização das relações de trabalho, com seus desdobramentos na precarização dos vínculos contratuais; nas condições inadequadas ao exercício profissional; na redução de quadro de pessoal; nos baixos salários etc. Estas não são expressões constitutivas da política de Assistência Social, mas são características da forma de regulação capitalista na atualidade.

As novas configurações do trabalho, com vistas à recuperação do ciclo de reprodução do capital, vêm afetando drasticamente as suas formas de realização no interior da esfera produtiva e de serviços, com a precarização estrutural do trabalho, aumento do desemprego, rebaixamento dos salários e precarização dos vínculos de emprego - que se dão através de contratações temporárias e terceirizadas, comprometendo diretamente os direitos trabalhistas e/ou previdenciários (ANTUNES, 2004).

Com a implantação do Suas, constatou-se um aumento significativo, por todo o território nacional, de contratação de diversos profissionais, dentre eles, os assistentes sociais, por meio de contratos sem vínculos empregatícios. Propiciando, desse modo, possíveis entraves na conformação de um quadro estável e qualificado, com a realocação e rotatividade de um contingente de trabalhadores na condição de prestadores de serviços, sem direitos trabalhistas e atuando de modo precarizado, subordinados a processos de alienação de sua autonomia técnica e intensificação do trabalho (RAICHELIS, 2010).

Mesmo com a NOB-RH/Suas definindo responsabilidades e atribuições aos gestores da política nas três esferas de governo, percebe-se, ainda, a conformação da lógica das terceirizações, com o processo de precarização do trabalho na prestação dos serviços socioassistenciais. Essas responsabilidades e atribuições dizem respeito à estruturação do trabalho, com equipes permanentes de profissionais de referências, de planos anuais de capacitação e da necessidade de assegurar recursos para promoção de 


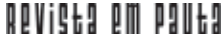

\} O SERVIÇO SOCIAL E AS CONDIÇÕES DE TRABALHO - HORA, S. S. |

DOI: 10.12957/rep.2015.21056

concursos públicos, estudos e pesquisas, com orçamento que garanta condições de trabalho e remuneração adequadas aos trabalhadores. Investindo, dessa maneira, na implantação do plano de capacitação e de isonomia, e estabelecendo parceria com o poder público enquanto estratégia para a garantia da qualidade da prestação dos serviços ofertados aos usuários.

O Suas, desse modo, só poderá ser implementado, de fato, com o fortalecimento de seus eixos estruturantes ${ }^{5}$. Isto é, com relações democráticas e afirmação de direitos; infraestrutura e condições materiais para qualificar a prestação de serviços e possibilitar o acesso dos usuários aos direitos socioassistenciais; com condições adequadas de trabalho; redução de jornada de trabalho; definição de remuneração compatível; processos continuados de capacitação e qualidade; ampliação do número de trabalhadores engajados etc.

A NOB-RH/Suas, aprovada em 2006 através da Resolução nº 269 do Conselho Nacional de Assistência Social, veio atender às necessidades, apontadas na Política Nacional de Assistência Social (PNAS) em 2004, de investimentos significativos por parte da esfera pública no que concerne aos recursos humanos, físicos e financeiros no âmbito da política (BRASIL, 2006).

Silveira (2011, p. 24) acrescenta que a referida NOB-RH "consolida os principais aspectos da legislação vigente para a gestão pública do trabalho, estabelecendo regras para sua aplicação e mecanismos reguladores da relação dos gestores com os trabalhadores dos serviços socioassistenciais". Para Ortolani (2011), a NOB-RH/Suas também representa uma grande conquista para a garantia da melhoria das condições de trabalho e da qualidade dos serviços socioassistenciais.

O autor citado também sinaliza que a Constituição Federal de 1988 prevê, em seu art. 37, inciso II, que a investidura em cargo ou emprego público deverá ser feita por aprovação prévia em concurso público. Além disso, que o $\mathrm{NOB} / \mathrm{RH}$ aponta para a composição mínima das equipes de referências no âmbito da Assistência Social, estabelecendo ainda que estas equipes sejam constituídas por servidores do quadro efetivo. No entanto, muitos municípios desconsideram essas prerrogativas de contratação pelo concurso público e da exigência de composição de quadros técnicos em número suficiente, com profissionais qualificados. Acabam, então, recorrendo a diversas formas de contratação através de terceirizações no serviço público, desrespeitando a exigência em lei do concurso público e muitas vezes sem garantias legais dos direitos trabalhistas (férias, 13ํㅗㄴ sário, FGTS) e/ou previdenciários (ORTOLANI, 2011).

${ }^{5}$ A política de recursos humanos constitui um dos eixos estruturantes do Suas, ao lado da descentralização políticoadministrativo e territorização; da matricialidade sociofamiliar; das novas bases para a relação entre Estado e Sociedade Civil; do financiamento; do controle social; e da informação, monitoramento e avaliação (PNAS, 2004). 


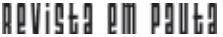

\} O SERVIÇO SOCIAL E AS CONDIÇÕES DE TRABALHO - HORA, S. S. \}

DOI: 10.12957/rep.2015.21056

Dentre as formas de contratação por terceirização, cabe mencionar as contratações por intermédio de Organizações Não Governamentais (ONGs) ou Organizações da Sociedade Civil de Interesse Público $(\mathrm{OSCIPs})^{6}$; a contratação "temporária por prazo determinado", "recibo de pagamento de autônomo" (RPA) e "cargos em comissão", preconizados pela Constituição Federal de $1988^{8}$ como cargos de livre nomeação e exoneração (SILVEIRA, 2011).

Em substituição ao concurso público, a flexibilização dos contratos de trabalho possibilita uma maior rotatividade de trabalhadores nos serviços do Suas, provocando, além da dicotomia entre os que possuem vínculos estáveis e os demais trabalhadores, divergências em termos de remuneração e de benefícios trabalhistas. A flexibilização, então, vem contribuindo para a descontinuidade das ações e a insegurança do trabalho pela ausência de estabilidade no serviço público (ORTOLANI, 2011).

O assistente social, ao vender a sua força de trabalho enquanto meio de subsistência, assim como qualquer trabalhador submetido ao regime econômico capitalista, também fica alienado do "controle sobre os meios de produção do seu trabalho, submetendo-se às normas regulatórias e hierarquias administrativas que organizam os serviços" (BARBOSA; CARDOSO; ALMEIDA, 1998, p. 118).

É no setor de serviços, principalmente aqueles sociais voltados para as demandas coletivas de reprodução social, que o assistente social se insere, prioritariamente. Como trabalhador assalariado, ele se submete aos mesmos constrangimentos inerentes ao conjunto da classe trabalhadora do setor de serviços.

Constata-se, desde a elaboração da NOB/RH/Suas, a fragilização na gestão do trabalho na política de Assistência Social no município de Rio Bonito. Considerando o histórico de precarização e a tendência ao rearranjo institucional na implementação dos serviços, algumas dificuldades podem ser sinalizadas no Quadro II.

Ao refletir, de forma crítica, sobre esses desafios que cercam o exercício profissional frente ao movimento histórico da sociedade brasileira e mundial, exigiu-se considerar o modo como o Serviço Social se insere na sociedade capitalista madura, enquanto fruto das relações antagônicas entre capital e trabalho, articulado aos processos de produção e reprodução das relações sociais.

Considera-se importante compreender as condições e relações de trabalho do assistente social como dimensão objetiva que confere mate-

\footnotetext{
${ }^{6}$ De acordo com os termos da Lei no 9790/99 e o Decreto nº 3100/99, que institui e disciplina o termo de terceirização (SILVEIRA, 2011).

${ }^{7}$ Conforme preconiza a Constituição Federal, no art. 37, inciso IX, na qual explicita que a contratação seja recorrida por excepcional interesse público (BRASIL, 1991)

${ }^{8}$ As funções de confiança e cargos em comissão, previstas na Constituição Federal, em seu art. 37, inciso V, destinamse apenas às atribuições de direção, chefia e assessoramento (BRASIL, 1991).
} 


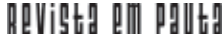

\} O SERVIÇO SOCIAL E AS CONDIÇÕES DE TRABALHO - HORA, S. S. \}

DOI: 10.12957/rep.2015.21056

rialidade ao seu fazer profissional, o que pressupõe também entender a dimensão subjetiva de sua intervenção. Isto é, a forma como esse profissional identifica o significado do seu trabalho, "as representações que faz da profissão, a intencionalidade de suas ações, as justificativas que elabora para legitimar sua atividade que orientam a direção social do exercício profissional" (RAICHELIS, 2010, p. 752).

Quadro II: fragilização na gestão do trabalho nos Cras e Creas

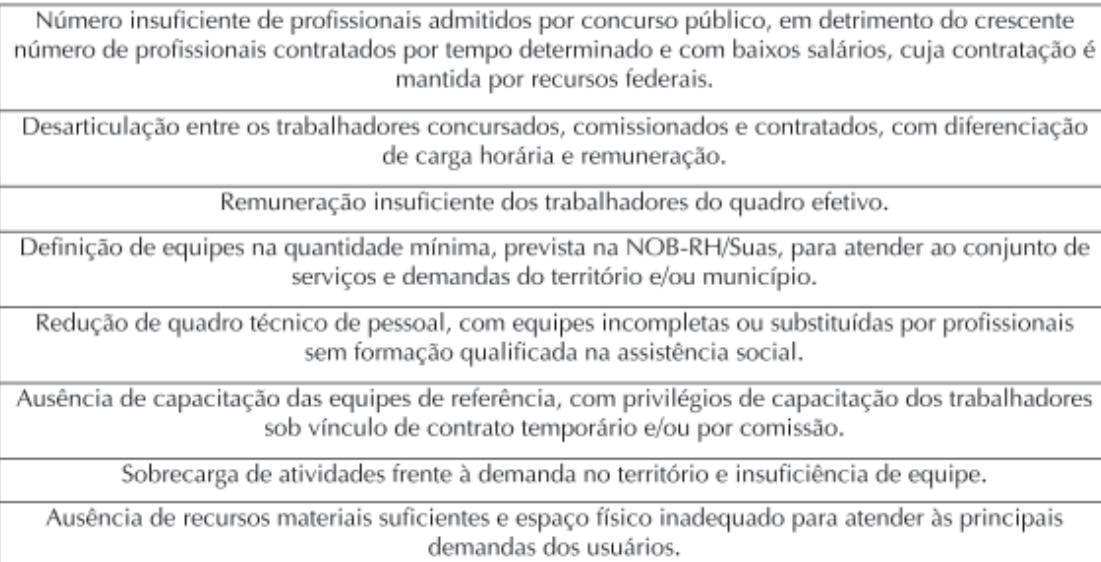

Fonte: relatos dos entrevistados. Ano: 2012/2013.

Apesar de ser regulamentado como profissional liberal, o assistente social não detém os meios necessários para efetivação do seu trabalho, pois depende da entidade empregadora para definir o público alvo, a forma de acesso dos usuários aos serviços e os meios e recursos para realização do trabalho. Isto acontece pois é a instituição que organiza o processo de trabalho no qual o assistente social se insere, na condição de assalariado.

O assistente social não trabalha isoladamente, mas como parte de um trabalho combinado ou coletivo. Logo, o significado do seu trabalho na órbita do Estado, na esfera dos serviços, é diferente daquele efetivado na esfera produtiva, no âmbito da empresa.

Na relação com o Estado não existe criação capitalista de valor e mais-valia porque o Estado não cria riquezas; contudo, recolhe parte da riqueza socialmente produzida sob a forma de tributos e outras contribuições que formam o fundo público, redistribuindo a parcela dessa mais-valia por meio de políticas sociais. Assim, a análise das características assumidas pelo trabalho do assistente social e de seu produto depende das características particulares dos processos de trabalho em que se insere (IAMAMOTO, 2007). 
No âmbito do Suas, evidencia-se uma ampliação de novas possibilidades de atuação para o assistente social, demandando desenvolvimento de novas habilidades e competências para a gestão pública, como: assessoria, planejamento, avaliação e monitoramento, entre outras. Essas novas exigências institucionais vêm desafiando o assistente social a avançar na perspectiva da competência crítica - de saber articular, no cotidiano de trabalho, as dimensões teóricas, técnicas, éticas e políticas.

Raichelis (2010), ao analisar as particularidades do trabalho do assistente social nos diferentes espaços sócio-ocupacionais no âmbito do Suas, aponta para os impactos das metamorfoses que afetam o trabalho assalariado na contemporaneidade, submetendo a atividade profissional aos dilemas da alienação. A autora ressalta que essa dinâmica societária atinge diversas profissões que têm nas políticas sociais um campo de intervenção, como o Serviço Social.

Esse processo de flexibilização expresso por trabalhos terceirizados, subcontratados e temporários, desprotegidos de direitos e desprovidos de organização coletiva, vem atingindo a realização concreta, a materialidade e as formas de subjetivação do trabalho assalariado.

A terceirização dos serviços públicos, no âmbito do Serviço Social, vem se expressando pela subcontratação de serviços individuais, por parte de órgãos privados de prestação de serviços públicos ou de assessoria técnica, "na prestação de serviços aos governos e organizações não governamentais, acenando para o exercício profissional privado (autônomo), temporário, por projeto, por tarefa, em função das novas formas de gestão das políticas sociais" (RAICHELIS, 2010, p. 759).

A ação desenvolvida pelos profissionais, por meio da subordinação a prazos contratuais, além de impossibilitar a continuidade do trabalho, também implica no rompimento dos vínculos dos profissionais com o usuário, levando a população ao descrédito dos serviços públicos.

Do ponto de vista da constituição do quadro profissional do Suas, no município de Rio Bonito, destaca-se ainda o universo heterogêneo de trabalhadores, compostos por profissionais contratados por tempo determinado, comissionados e concursados. Dos seis assistentes sociais ${ }^{9}$ dos Cras e Creas entrevistados, verificou-se que todos são do sexo feminino, demonstrando traços de uma profissão atravessada por relações de gênero, interferindo na sua imagem junto à sociedade quanto ao reconhecimento social e acadêmico.

A NOB RH/Suas prevê a formação de equipes de referência, que devem ser constituídas por servidores efetivos responsáveis pela organização e oferta de serviços, programas, projetos e benefícios de Proteção Social Básica e Especial. No entanto, os dados apontaram uma grande discrepância

\footnotetext{
${ }_{9}^{9}$ Foram entrevistadas duas assistentes sociais do Cras 1 (Basílio), uma assistente social do Cras 2 (Boa Esperança), uma assistente social do Cras 3 (Centro) e duas assistentes sociais do Creas.
} 


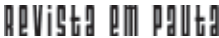

\} O SERVIÇO SOCIAL E AS CONDIÇÕES DE TRABALHO - HORA, S. S. \}

DOI: 10.12957/rep.2015.21056

em relação aos tipos de vínculos e carga horária das profissionais inseridas nos mesmos espaços sócio-ocupacionais.

$\mathrm{Na}$ análise sobre o processo de trabalho no Suas, é preciso considerar o trabalho do assistente social sob a ótica do trabalho coletivo enquanto trabalho social e combinado, orientado por um projeto profissional vinculado a outro societário (IAMAMOTO, 2007).

A pesquisa sobre o trabalho do assistente social nos Cras e Creas de Rio Bonito encaminhou-se também para compreensão dos elementos do cotidiano de trabalho das seis profissionais entrevistadas, tendo como eixo de análise a tensão entre trabalho assalariado e projeto profissional.

Busca-se, assim, tornar visíveis as tensões entre o direcionamento ético e político que o assistente social pretende imprimir ao seu trabalho, bem como as exigências que a instituição empregadora impõe ao trabalhador assalariado. Dessa forma, optou-se por organizar as respostas de cada entrevistada sob a forma de citação.

Os dados a seguir irão explicitar as respostas das profissionais entrevistadas sobre diferentes questões que perpassam o cotidiano de trabalho nos diferentes espaços sócio-ocupacionais do Suas no município estudado.

Cada questão ressaltada revela uma preocupação pela busca de estratégias políticas de organização coletiva para o enfrentamento dos constrangimentos a que são submetidos os assistentes sociais na relação com os empregadores e dirigentes institucionais, frente aos processos de precarização do trabalho.

Em relação ao processo de trabalho, é possível perceber que a realização do trabalho se reafirma como resultado de um coletivo, um trabalho de equipe multiprofissional, atuando de forma ampla e construindo respostas profissionais às complexas e múltiplas demandas da realidade, objetivadas nas necessidades sociais. Em síntese, a intervenção do assistente social é vista a partir de sua relação com o usuário, com os empregadores e com os demais profissionais. Logo, é uma atividade laboral socialmente determinada, que depende das condições sociais que circundam a sua realização, bem como das relações sociais por meio das quais se realiza. É o que explicita uma das entrevistadas:

O assistente social se insere no universo coletivo interdisciplinar e multidisciplinar. Por se tratarem de demandas diversificadas, necessitamos de articulação com profissionais de conhecimentos distintos para a construção de um trabalho coletivo. O profissional se relaciona com a equipe por meio de demandas específicas que exigem articulação de diferentes profissionais (principalmente da psicologia). É uma relação de reciprocidade. (Assistente social B - Cras 1).

Em relação ao registro e à sistematização do exercício profissional, percebeu-se a falta de clareza sobre o seu significado. Não é visível a compreensão da sistematização enquanto uma reflexão teórica (ALMEIDA, 2009), 


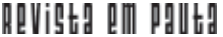

\} O SERVIÇO SOCIAL E AS CONDIÇÕES DE TRABALHO - HORA, S. S. \}

DOI: $10.12957 /$ rep.2015.21056

seja da realidade social, seja das respostas profissionais frente às expressões da questão social. Logo, não é uma estratégia endógena à própria profissão e nem uma mera atividade esporádica, um apêndice ou registro diário, como aparece nos relatos; é, porém, uma atividade que faz parte da própria dinâmica do trabalho coletivo realizado por profissionais com diferentes formações.

A sistematização do nosso trabalho ocorre através de registros em prontuários e livro de ocorrência. (Assistente social F - Creas).

Através de prontuários individualizados; relatórios de visitas domiciliares; relatórios de reunião de equipe; registro de estudo de caso; relatórios para outros órgãos, Conselho Tutelar, Promotoria, MP, entre outros. (Assistente social C - Cras 2).

A sistematização pressupõe a consolidação de um trabalho voltado à socialização das experiências profissionais, não apenas em formas de relatos descritivos das atividades cotidianas, mas enquanto processo de sistematização (reflexão teórica) das mesmas, que contribua para o amadurecimento intelectual e reconhecimento social da nossa profissão. Isso requer de nós um grande esforço intelectual e de mediação das dimensões teóricometodológica, ético-política e técnico-operativa (ALMEIDA, 2009).

Sobre os desafios postos ao Serviço Social no âmbito da Política de Assistência, cabe ressaltar alguns relatos das entrevistadas:

O grande desafio posto ao Serviço Social é a reafirmação no cotidiano de trabalho de uma intervenção pautada no reconhecimento da liberdade, autonomia e emancipação dos usuários, visando à ampliação e à consolidação da cidadania. Os desafios postos ao Serviço Social são: a luta por melhores condições de trabalho e a expansão dos direitos, na perspectiva da ampliação da proteção social. (Assistente social A - Cras 1).

Romper com interesses específicos ou corporativos de um segmento. O grande desafio para o Serviço Social é o de atuar na perspectiva de efetivar a assistência social enquanto política pública e materializar o acesso da população aos direitos sociais. (Assistente social E - Creas).

Sobre as possibilidades e os limites para a atuação do Serviço Social e efetivação do projeto profissional neste campo de atuação, é possível evidenciar, nas falas, a relativa autonomia profissional associada às precárias condições e relações de trabalho:

Limites: melhores condições materiais, institucionais, físicas e financeiras necessárias para a execução da assistência social e que garanta o atendimento das demandas dos usuários. Relações de trabalho está- 


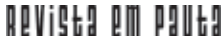

\} O SERVIÇO SOCIAL E AS CONDIÇÕES DE TRABALHO - HORA, S. S. |

DOI: 10.12957/rep.2015.21056

veis asseguradas por concurso público e contrato de trabalho que garanta direitos trabalhistas, assim como salários condizentes com a função, jornada de trabalho e capacitação. Possibilidades: a relativa autonomia de trabalho que assegura o direito de realizar escolhas técnicas no âmbito da decisão democrática, liberdade para pesquisar, planejar e avaliar o trabalho em conjunto com outros profissionais e com os usuários dos serviços. O Projeto Ético-Político vem se consolidando no exercício profissional. (Assistente social A - Cras 1).

O profissional encontra mais limites do que possibilidades para a reafirmação do projeto profissional. Os limites apontam para a precarização do trabalho, sob a lógica dos vínculos temporários que não permitem a continuidade do trabalho desenvolvido. (Assistente social D - Cras 3).

Falta de condições materiais e estruturais de trabalho e o modelo econômico vigente. (Assistente social E - Creas).

Limites e interesses institucionais, falta de recursos e acomodação de alguns profissionais. A possibilidade de reafirmação do projeto vai depender da capacidade ética e do compromisso do profissional. Nesse sentido, pode-se afirmar que mesmo diante dos limites estruturais, o Projeto Ético-Político tem sido efetivado no processo de trabalho. (Assistente social F - Creas).

A pesquisa permite entender como os principais dilemas contemporâneos se traduzem nas peculiaridades da profissão e se expressam nas requisições e competências profissionais. Vários limites apontados pelas entrevistadas reforçam a preocupação com as novas formas de organização e gestão do trabalho, que contemple as condições materiais, institucionais, físicas e financeiras necessárias para a execução da política de Assistência Social. Além disso, também os meios e instrumentos necessários ao exercício profissional, com a ampliação do número de trabalhadores, ao lado de processos continuados de capacitação, realização de concursos públicos de ingresso, plano de cargos, carreira e salários, entre outros.

Quanto aos limites e possibilidades para a atuação do Serviço Social e efetivação do projeto profissional, ainda é evidente a falta de clareza do que é o Projeto Ético-Político Profissional. Observa-se a forma pragmática de compreensão deste projeto, que aparece como manual de procedimentos para padrões de atuações. Cabe destacar a forma como o projeto profissional é reduzido à intencionalidade, isto é, à capacidade técnica e à vontade do profissional de efetivação do projeto idealizado:

A efetivação do projeto depende do comprometimento técnico e do trabalho em equipe multiprofissional. (Assistente social C - Cras 2).

Mesmo com todos os limites expressos nas relações e condições de trabalho, ainda é possível efetivar o projeto no cotidiano do trabalho, 


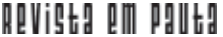

\} O SERVIÇO SOCIAL E AS CONDIÇÕES DE TRABALHO - HORA, S. S. \}

DOI: $10.12957 /$ rep.2015.21056

porque depende da capacidade propositiva, técnica e crítica do profissional. (Assistente social D - Cras 3).

Podemos, ainda, identificar a forma como as assistentes sociais compreendem a autonomia relativa do fazer profissional e as tensões entre projeto profissional e trabalho assalariado.

Quanto mais restrita for essa autonomia, mais difícil será a efetivação do projeto profissional. (Assistente social A - Cras 1).

Precisamos alargar essa autonomia relativa, que cada vez mais tem sido constrangida pelo trabalho assalariado. Não temos o domínio do processo de trabalho, da forma de organização dos serviços, e muitas vezes a instituição ainda quer definir a forma de intervenção do profissional - delimitando o tipo de instrumental e técnicas utilizadas, mas esse domínio é de autonomia relativa do profissional. (Assistente social B - Cras 1).

A relativa autonomia e o projeto profissional devem caminhar juntos. (Assistente social C - Cras 2).

Relativa autonomia e projeto profissional: uma relação possível, mas também uma relação contraditória. (Assistente social F - Creas).

É importante notar a forma como a relativa autonomia é retratada pelas profissionais, ou seja, como condição para efetivação do Projeto ÉticoPolítico Profissional. Por outro lado, não percebem que essa relativa autonomia também incide na compreensão da realidade social, que implica no desvelamento da aparência, a fim de capturar a essência das mediações que conectam os complexos sociais constitutivos e constituintes da totalidade do ser social (NETTO, 2009b).

Quando não se reconhecem as relações sociais por meio das quais se realiza o trabalho do assistente social, corre-se o risco de reduzir o projeto profissional ao discurso da vontade política do profissional (IAMAMOTO, 2007).

Perceber a realidade como totalidade, apanhando as contradições do real, de modo a perseguir suas mediações, possibilita ao assistente social a captação de saberes explicativos e interventivos para o enfrentamento das contradições que se encontram na essência dessa própria realidade.

A luta pela reafirmação e efetivação do Projeto Ético-Político tem sido a grande estratégia de alargamento da relativa autonomia profissional contra a alienação do trabalho assalariado no cotidiano dos espaços sócioocupacionais (RAICHELIS, 2010). Contudo, é preciso ter clareza sobre os limites da ação profissional no que diz respeito ao direcionamento social no qual pretende imprimir sua intervenção, e as reais condições concretas que circunscrevem o seu trabalho, assim como o agravamento das refrações sociais. Sem essa compreensão da realidade social, o profissional tende a 


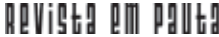

\} O SERVIÇO SOCIAL E AS CONDIÇÕES DE TRABALHO - HORA, S. S. \}

DOI: 10.12957/rep.2015.21056

perder a perspectiva da história, ficando aquém das possibilidades que a realidade enseja ou numa utopia romântica de idealização das possibilidades, para muito além do que seu mandato institucional lhe permite (IAMAMOTO, 2007).

Não podemos negar as possibilidades de ação contidas na realidade social, mas é imprescindível a construção de propostas profissionais concernentes ao nosso tempo histórico. Estas devem ser capazes de "articular as lutas institucionais, vividas no cotidiano profissional, com as lutas mais gerais da sociedade em defesa das políticas públicas universais e de responsabilidade do Estado" (BRAVO, 2009, p. 704).

Ao longo da pesquisa, foi possível perceber alguns equívocos em relação à percepção do que é o Projeto Ético-Político. Os dados sinalizam uma tendência à individualização de um projeto que é coletivo. Além disso, também a falta de conhecimento sobre os elementos do Projeto ÉticoPolítico, que permeiam a formação, e a sua falta de clareza da materialidade $^{10}$ no cotidiano de trabalho, que não é apresentado pelas entrevistadas como um produto das relações societárias, solidificando a "autoimagem" da profissão e a unicidade da categoria. Da mesma forma, vale destacar o desconhecimento da intencionalidade nas ações materializadas pelos sujeitos - sejam elas conscientes ou não -, pois a categoria profissional aparece como uma representação de um coletivo sem direção social.

Em relação às competências e atribuições profissionais, é notável a predominância, na política de Assistência Social, de uma atuação pautada em abordagens individuais, familiares ou grupais.

Há uma tendência à padronização de rotinas e procedimentos de intervenção, em que os profissionais buscam referenciar sua atuação pela tipificação dos serviços. É uma espécie de "tecnificação" dos atendimentos/acompanhamentos, restringindo as inúmeras possibilidades de construção de respostas competentes, sintonizadas com a complexidade e dinamicidade da realidade social.

A definição das estratégias e o uso dos instrumentais técnicos devem ser estabelecidos pelo próprio profissional, e não pelo órgão gestor. $\mathrm{O}$ instrumento, enquanto elemento dinâmico e potencializador da ação, envolve um conjunto de recursos ou meios que permitem ao assistente social objetivar as finalidades de sua intervenção profissional (GUERRA, 2008).

Outra ambiguidade de conceituação encontra-se na forma como os usuários são identificados pelos profissionais, o que demonstra a incorporação dessa definição pela própria política de Assistência Social.

Os usuários são famílias e indivíduos em situação de risco e em vulnerabilidade social. (Assistente social A - Cras 1).

\footnotetext{
${ }^{10}$ As entrevistadas pareciam desconhecer a materialidade do Projeto Ético-Político nos três marcos legais da profissão: o Código de Ética do Assistente Social (1993), a Lei de Regulamentação da Profissão (1993) e as Diretrizes Curriculares norteadoras da formação acadêmica (Abess/Cedepss, 1996, 1997a, 1997b; MEC-Sesu/Coness/Comissão de Especialistas de Ensino em Serviço Social, 1990; MEC-SESU, 2001). (IAMAMOTO, 1998).
} 
População em situação de risco e/ou em vulnerabilidade social. (Assistente social D - Cras 3).

Famílias ou indivíduos em situação de risco e/ou vulnerabilidade social, decorrente de violação de direitos. (Assistente social E - Creas).

Indivíduos que possuem os seus direitos violados e se encontram em risco social. (Assistente social F - Creas).

Os discursos "plagiados", carregados de forte conotação liberal, como vulnerabilidade social, vigilância social e empowerment (empoderamento), são reproduzidos no cotidiano institucional sem nenhuma clareza dos seus significados. Em nenhuma resposta há a identificação do usuário enquanto pertencente à classe trabalhadora.

Quando questionadas sobre a existência de alguma relação do Projeto Ético-Político Profissional com o Suas, todas as entrevistadas responderam afirmativamente, justificando o motivo dessa relação:

Pois, o Suas tem sido uma grande conquista de reconhecimento e consolidação da cidadania. Assim como o Projeto Ético-Político Profissional, esse sistema visa à expansão dos direitos e à emancipação dos usuários. (Assistente social A - Cras 1).

Os próprios princípios e diretrizes do Suas possuem articulação com o nosso projeto profissional. Por isso, o projeto profissional só será efetivado quando os princípios do Suas e do RH-Suas forem amplamente efetivados. (Assistente social B - Cras 1).

Defender o Suas é defender o Projeto Ético-Político Profissional. Esse projeto, para ser efetivado, depende do comprometimento técnico, do trabalho em equipe multiprofissional e de empoderamento ético e político. (Assistente social D - Cras 3).

O Suas e o Projeto Profissional visam à construção de uma nova ordem societária, com sua gestão democrática em favor da equidade e justiça social. Esse projeto é a única forma de consolidar nossa profissão e o nosso trabalho no Suas. (Assistente social E - Creas).

Cabe mencionar a forma como o Projeto Ético-Político aparece nas falas como um projeto que se iguala ao Suas. A expressão "defender o Suas é defender o Projeto Ético-Político Profissional ${ }^{11 "}$ é reveladora de uma grande tendência a confundir a profissão com a política de Assistência Social.

O Suas, mesmo representando a capacidade política de resistência dos atores envolvidos, na direção do reconhecimento legal da Assistência

\footnotetext{
${ }^{11}$ Relato da entrevistada (assistente social D) do Cras 3.
} 


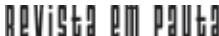

\} O SERVIÇO SOCIAL E AS CONDIÇÕES DE TRABALHO - HORA, S. S. \}

DOI: 10.12957/rep.2015.21056

Social como política pública, ainda possui uma perspectiva liberal: de provisão de mínimos sociais, que auxiliam no atendimento das carências humanas (sem abrir mão da contrapartida do usuário do sistema); de atenção minimalista e seletiva, que não contempla todos que demandam os serviços, mas os que mais precisam; de amenização e controle das mazelas sociais, legitimando ideologicamente a ordem e readequando os programas e projetos sociais ao atendimento da extrema pobreza, em tempos de extinção e de precarização de postos de trabalho; e de criação de uma massa de desempregados permanentes.

Precisamos compreender que o projeto profissional preconiza o reconhecimento da liberdade, da autonomia, da emancipação e da plena expansão dos indivíduos sociais. Um projeto coletivo, cujo compromisso ético-político profissional pauta-se na defesa intransigente dos direitos humanos e na recusa do arbítrio e do autoritarismo; na ampliação e consolidação da cidadania; na defesa do aprofundamento da democracia; no posicionamento em favor da equidade e justiça social; e no empenho da eliminação de todas as formas de preconceito (CFESS, 1993).

\section{Considerações finais}

É inquestionável que a crise estrutural do capital vem provocando profundas mudanças no redirecionamento do papel do Estado, com o toque do privatismo da ideologia neoliberal, a partir da defesa de uma desqualificação das funções estatais. Isto pressupõe uma erosão das regulações sob o discurso de um Estado mínimo, visando claramente à liquidação de direitos sociais e ao assalto ao patrimônio e ao fundo público (NETTO, 1996).

Por outro lado, também se observa que o momento coetâneo tem sido profícuo no que se refere à ampliação dos espaços sócio-ocupacionais. Isto advém do processo de descentralização das políticas sociais, com ênfase na municipalização, exigindo dos assistentes sociais novas funções e competências. Conforme ressalta lamamoto (2007, p. 208), a contemporaneidade brasileira demanda profissionais com um perfil "culto, crítico e capaz de formular, recriar e avaliar propostas que apontem para a progressiva democratização das relações sociais".

A política de Assistência Social, a partir da implementação do Suas, sofreu mudanças significativas, refletindo impactos na organização do trabalho coletivo nos Centros de Referência, na composição das equipes e nas rotinas institucionais. A municipalização das políticas públicas vai ampliar o mercado de trabalho do assistente social e sua participação na gestão social pública, ou gerencial pública, requerendo uma qualificação desse profissional. Isso amplia o "leque" de atribuições para os assistentes sociais (IAMAMOTO, 1998). 


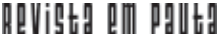

\} O SERVIÇO SOCIAL E AS CONDIÇÕES DE TRABALHO - HORA, S. S. \}

DOI: $10.12957 /$ rep.2015.21056

No entanto, o desafio que se impõe refere-se à universalização deste direito, necessitando maior investimento estatal para que a Assistência Social se torne de fato uma política pública universal.

Dessa forma, considero que os avanços da Assistência Social no município de Rio Bonito (RJ) são notados a partir da implementação da Loas e do Suas, que trouxeram uma nova forma de encarar a Assistência Social. Estes passam, assim, a ser vistos como direito do cidadão e dever do Estado.

Observam-se algumas mudanças ocorridas na política de Assistência Social com a implementação do Suas no município estudado. Estas, na atualidade, incidem sobre o exercício profissional do assistente social, tanto do ponto de vista teórico-metodológico, quanto ético-político e técnico-operativo. Nesse contexto tão adverso, em que a contrarreforma do Estado e todas as outras alterações promovidas a partir da acumulação do capital têm se constituído como um gigantesco limite, os profissionais de Serviço Social são desafiados a efetivar o Projeto Ético-Político Profissional no sentido da construção de uma contraideologia que questione os pilares de sustentação da ordem vigente.

Os profissionais sintonizados com o ritmo acelerado das mudanças são hábeis para problematizar suas possibilidades reais de transformação da realidade. Porém, isto não significa realização imediata, pois não se transforma a realidade apenas pelo pensamento ou pela consciência das alternativas e estratégias de projeção de finalidades (MARX; ENGELS, 1998).

Entendo que os profissionais que atuam conforme o projeto profissional crítico conseguem forjar estratégias que valorizem a vida e contribuam para a radicalização da democracia, da liberdade e da cidadania. São profissionais que possuem maior clareza sobre seus compromissos éticos e políticos, capazes de escolher com responsabilidade suas estratégias e táticas, conhecendo os limites impostos pela condição de trabalhador assalariado, como também as possibilidades de ampliação e/ou alargamento de sua relativa autonomia.

Para finalizar - sem, no entanto, pretender concluir essas análises - volto ao eixo central da proposta, afirmando que as relações sociais que circundam o trabalho do assistente social interferem decisivamente no significado social do seu trabalho. Assim, tornam-no impregnado de dilemas da alienação e de determinações sociais que afetam a qualidade do exercício profissional, com a subordinação do conteúdo do trabalho aos objetivos e necessidades das entidades empregadoras. Este contexto leva o assistente social a exercer um trabalho muito mais burocratizado e rotineiro.

Nesse sentido, cabe mencionar a forma como se processam as respostas dos assistentes sociais entrevistados em relação às demandas dos usuários que buscam pelo Serviço Social, no âmbito da política de Assistência Social do município de Rio Bonito (RJ). Evidenciam-se respostas permeadas por uma atuação imediata e pontual, sem planejamento neces- 


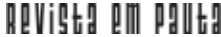

\} O SERVIÇO SOCIAL E AS CONDIÇÕES DE TRABALHO - HORA, S. S. \}

DOI: 10.12957/rep.2015.21056

sário. Em relação ao processo de trabalho no Suas, ainda é predominante a inserção dos assistentes sociais nos Cras e Creas do município de Rio Bonito (RJ) por meio de contrato precarizado. Ou seja, através de processo seletivo simplificado, de caráter temporário, crivado pelo tráfico de influências, descumprindo a prerrogativa constitucional de contratação pela via do concurso público.

A classe trabalhadora vem sofrendo a mais aguda crise do século no que diz respeito à materialidade, subjetividade e na sua forma de ser. Os principais impactos que o mundo do trabalho vem sofrendo, no marco da reestruturação produtiva e da mundialização do capital, decorrem da precarização dos empregos (ANTUNES, 2004).

Com os rebatimentos da contrarreforma do Estado, as condições sociais que permitem a realização do trabalho do assistente social tendem a ser desreguladas e flexibilizadas, com precárias condições e relações de trabalho. É nesse terreno denso de tensões e contradições que se insere o assistente social, na condição de trabalhador assalariado, sujeito à adequação das exigências alheias e ao trabalho alienado. O desafio de alargamento da relativa autonomia na condução do exercício profissional tem sido o primeiro passo que condiciona a possibilidade de realização dos resultados projetados e de materialização do projeto profissional em diferentes espaços ocupacionais (IAMAMOTO, 2007).

Os assistentes sociais entrevistados ponderam sobre as precárias condições de trabalho, tais como: espaços físicos insuficientes, contratos de trabalho instáveis, instabilidade e insegurança no emprego, baixas remunerações e outros constrangimentos do trabalho assalariado. Conforme sinalizado na hipótese desta pesquisa, estas condições inflexionam as possibilidades de materialização do Projeto Ético-Político Profissional uma vez que impõem uma posição de submissão do profissional no espaço sócio-ocupacional, com o comprometimento da qualidade dos serviços e da estratégia de alargamento de sua relativa autonomia.

Outro fator importante que merece ser mencionado é a defesa da qualidade dos serviços sociais prestados, pois o efetivo funcionamento dos Cras e Creas é imprescindível para o desempenho de suas funções e oferta com qualidade de serviços socioassistenciais. Constituem alguns dos elementos a serem observados para o funcionamento dos Cras e Creas: espaço físico, recursos humanos e materiais, período de funcionamento e identificação. A preocupação com esses itens se deve ao fato de que a realidade atual denuncia o grande desafio a ser enfrentado no âmbito dessa política: a superação da concepção da Assistência Social como uma política pobre, destinada aos mais pobres, por meio de ações pobres, ofertadas em unidades pobres.

Nos diferentes espaços ocupacionais, o assistente social busca realizar uma ação de cunho sociopolítico que, de acordo com lamamoto (2009), vai além da garantia dos direitos sociais aos usuários que demandam 


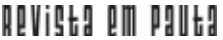

\} O SERVIÇO SOCIAL E AS CONDIÇÕES DE TRABALHO - HORA, S. S. \}

DOI: 10.12957/rep.2015.21056

serviços nas instituições e organizações nas quais trabalha. A sua ação também afirma compromisso com a garantia e defesa da qualidade dos serviços sociais. Por isso, lamamoto (2009, p. 25) menciona a necessidade de um novo tipo de profissional "propositivo" pois, segundo ela, "o exercício da profissão exige um sujeito profissional que tenha competência para propor, para negociar com a instituição os seus projetos e para defender o seu campo de trabalho, suas qualificações e atribuições profissionais". 


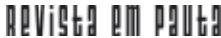

\} O SERVIÇO SOCIAL E AS CONDIÇÕES DE TRABALHO - HORA, S. S. \}

DOI: 10.12957/rep.2015.21056

\section{Referências}

ALMEIDA, N. L. T. A sistematização da prática em Serviço Social. In: MOTA, A. E. et al. (org.). Serviço Social e saúde: formação e trabalho profissional. São Paulo: Cortez. 2009.

ALMEIDA, N. L. T.; ALENCAR, M. T. Serviço Social: trabalho e políticas públicas. Rio de Janeiro: Saraiva. 2011.

ANTUNES, R. Adeus ao trabalho? Ensaio sobre as metamorfoses e a centralidade do mundo do trabalho. São Paulo: Cortez. 2004.

BARBOSA, R. N.; CARDOSO, F. G.; ALMEIDA, N. L. A categoria processo de trabalho e o trabalho do assistente social. Serviço Social e Sociedade. São Paulo: Cortez, n. 58. 1998.

BRASIL. Constituição da República Federativa do Brasil, 1988. São Paulo: Editora Revista dos Tribunais. 1991.

. Norma operacional básica do Sistema Único de Assistência Social - NOB SUAS. Brasília: MDS. 2005.

. Norma operacional básica do Sistema Único de Assistência Social - NOB SUAS. Brasília: MDS. 2012.

. Norma operacional básica de Recursos Humanos do Sistema Único de Assistência Social - NOB SUAS. Resolução CNAS n. 269, de 13 de dezembro de 2006. Brasília: MDS. 2006.

BRAVO, M. I. S. Política de saúde no Brasil. In: MOTA, A. E. et al. (org.). Serviço Social e saúde: formação e trabalho profissional. São Paulo: Cortez. 2009.

CFESS. Código de ética profissional dos assistentes sociais. 1993. Disponível em: <www.cfess.org.br/arquivos/CEP_1993.pdf.>. Acesso em:11/03/2013.

$\mathrm{GOHN}$, M. da G. M. A pesquisa nas ciências sociais. Considerações metodológicas. Cadernos Cedes. São Paulo: Cortez, n. 12. 1984.

GUERRA, Y. A instrumentalidade do trabalho do assistente social. In: SIMPÓSIO MINEIRO DE ASSISTENTES SOCIAIS. Belo Horizonte: Cress $6^{\underline{a}}$ Região. 2008.

IANNI, O. A tentação metodológica. In: A sociologia e o mundo moderno. Rio de Janeiro: Civilização Brasileira. 2011.

IAMAMOTO, M. V. O Serviço Social na contemporaneidade: trabalho e formação profissional. São Paulo: Cortez. 1998.

. Capital fetiche, questão social e Serviço Social. In: Serviço Social em tempo de capital fetiche: capital financeiro, trabalho e questão social. São Paulo: Cortez. 2007.

. O Serviço Social na cena contemporânea. In: CFESS; ABPESS. Serviço Social: direitos sociais e competências profissionais. São Paulo: Cortez. 2009. 


\section{ReVigta dil pallt}

\} O SERVIÇO SOCIAL E AS CONDIÇÕES DE TRABALHO - HORA, S. S. \}

DOI: 10.12957/rep.2015.21056

IAMAMOTO, M. V.; CARVALHO, R. Relações sociais e Serviço Social no Brasil. São Paulo: Cortez. 2012.

LEFÉBVRE, H. Teoria do conhecimento. In: Lógica formal, lógica dialética. Rio de Janeiro: Civilização Brasileira. 1975.

MARX, K.; ENGELS, F. Manifesto comunista. São Paulo: Boitempo. 1998.

CRUZ NETO, O. O trabalho de campo como descoberta e criação. In: MINAYO, M. C. de S. (org.). Pesquisa social: teoria, método e criatividade. Petrópolis: Vozes. 1994.

NETTO, J. P. Introdução ao método da teoria social. In: Serviço Social - direitos sociais e competências profissionais. Brasília: CFESS/Abepss. 2009a.

A construção do projeto ético-político do Serviço Social. In: MOTA, A. E. et al. (org.). Serviço Social e saúde: formação e trabalho profissional. São Paulo: Cortez. 2009b.

- Ditadura e serviço social. Uma análise do serviço social pós-64. São Paulo: Cortez. 1991.

. Transformações societárias e serviço social: notas para uma análise prospectiva da profissão no Brasil. Serviço Social e Sociedade. São Paulo: Cortez, n. 50. 1996.

ORTOLANI, F. Desafios para a consolidação da NOB-RH/SUAS nos municípios. In: V JORNADA INTERNACIONAL DE POLÍTICAS PÚBLICAS. São Luís: Ufma. 2011.

PNAS. Resolução no 145, de 15 de outubro de 2004, do Conselho Nacional de Assistência Social. Brasília: Diário Oficial da União, 28 out. 2004.

RAICHELIS, R. Intervenção profissional do assistente social e as condições de trabalho no SUAS. Serviço Social e Sociedade [on-line]. São Paulo: Cortes, n. 104. 2010.

SILVEIRA, J. I. A centralidade do trabalho e da formação continuada no SUAS: realidade e agenda política. In: VIII CONFERÊNĆIA NACIONAL DE ASSISTÊNCIA SOCIAL: CONSOLIDAR O SUAS E VALORIZAR SEUS TRABALHADORES. Brasília: Conselho Nacional de Assistência Social. 2011.

Recebido em 30 de julho de 2015.

Aprovado para publicação em 31 de outubro de 2015.

DOI: $10.12957 /$ rep.2015.21056

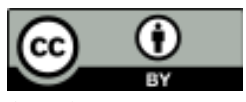

A Revista Em Pauta: Teoria Social e Realidade Contemporânea está licenciada com uma Licença Creative Commons Atribuição 4.0 Internacional. 